\author{
By Pedrum Mohammadi-Shemirani
}

\title{
Interview with Dr. Alexis Carere: Manager at Ontario Genomics
}

Dr. Alexis Carere is a postdoctoral research fellow and genetic counsellor in the Genetic and Molecular Epidemiology Laboratory, led by Dr. Guillaume Paré, in the Department of Pathology and Molecular Medicine at McMaster University, Hamilton, Canada.

Her previous education includes an ScD in Epidemiology from the Harvard T.H. Chan School of Public Health, an MS in Genetic Counseling from the University of North Carolina at Greensboro, an MA in Philosophy from Western University, and an HBSc in Genetics from Western University.

Her current position comprises both clinical and research roles. On the clinical side, she provides genetic assessment and counselling of patients with suspected hereditary cardiovascular disease at the Hamilton General Hospital Lipids Genetics Clinic. Meanwhile, her primary academic research is focused on using genetic epidemiology and statistical genetics methods, such as Mendelian randomization, to identify novel causal blood biomarkers for Alzheimer's disease.

\section{How did your graduate education prepare you for your career?}

In some ways my graduate training was very specific: I have a Master of Science in Genetic Counselling, and I am now a board-certified genetic counsellor; I have a Doctor of Science in Epidemiology, and I am now a postdoctoral fellow in Epidemiology. That said, my graduate training has also turned out to be interrelated and complementary. My experience in genetic counselling and clinical care has informed my work in epidemiology, and given me the ability to carve out a research space for myself that is unique. My training in epidemiology and biostatistics has helped me be a better genetic counsellor, because I am able to critically evaluate the relevant science that forms the basis of our profession, in order to provide evidence-based care. I also have a Master of Arts in Philosophy, and that has been foundational for

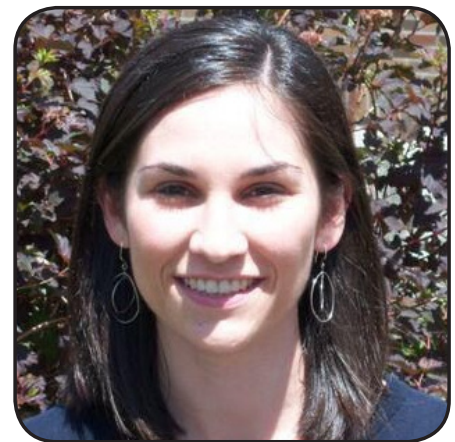

me as I think about and address (in both patient care and research) the bioethical issues inherent to medical genetics.

\section{What is your average day/week like? Can you} describe a current project you are working on?

Every day and every week is a little bit different! Some days I am in clinic, so I am seeing patients with suspected genetic disease (in my current setting, that means patients with a history of cardiovascular disease - heart attack or stroke - that is strikingly young, recurrent, or seems to run in the family). Other days I am working with a team to review the results of our exome sequencing research, in which we try to identify the molecular causes of some of the cases we see in the clinic. In addition to evaluating individual cases, we are always trying to improve the way this research is done, and thinking about how best to integrate genetic sequencing into clinical care. I am also often conducting epidemiological research, which means performing statistical analyses on the computer, and then writing up the results of the analyses as scientific papers. Right now I'm working on an analysis of blood biomarkers for Alzheimer disease. Being a postdoctoral fellow involves a lot of hours spent in front of the computer, designing and tweaking analyses, and trying to figure out how best to present your findings to the research community.

\section{What is your favourite and least favourite part about the job?}

My favourite part is working with patients, and helping them to engage with genetics and genetics research. My second favourite part is attending scientific conferences, where I get to meet lots of cool people and learn the newest science. My least favourite part is probably endless revisions of papers, both before submission and after review. Meeting journal formatting requirements can be really tedious, and trying to stay true to the paper 
you want to write while addressing reviewer suggestions can sometimes be a challenge. At least on the other end of it all, there is usually a publication, so it is well-rewarded work!

\section{What is the current demand for MSc or PhD students in your field?}

Genetic counsellors in Canada and the United States are required to train through an accredited program, and to pass their country's certification exam, so the demand for specific training is high within the profession. More generally, the job market for genetic counsellors is excellent in both countries (many counsellors move back and forth between the two during training and employment, or even work remotely across borders). You don't need a doctorate to be a genetic counsellor; on the other hand, the past few years have seen an increase in genetic counsellors obtaining doctorates, and an increase in the career opportunities open to them. The neat thing is that a genetic counsellor could go in a lot of different directions with doctoral training - molecular genetics, psychology, epidemiology, counselling, etc. - which each open up different career paths. There are opportunities throughout academic research, clinical care, and industry.

\section{Do you have any advice for current graduate students who would like to envisage a similar career path?}

Talk to a genetic counsellor! In fact, talk to different genetic counsellors, working in different industries or settings. We used to talk about "traditional" versus "non-traditional" genetic counselling jobs, but that's really an outdated way of looking at things. Today, becoming a genetic counsellor doesn't have to mean signing up to provide reproductive genetic counselling to expectant couples (unless you want to!), so you may get a narrow view of the profession if you only speak with prenatal counsellors, for example. As it pertains to your interests, try contacting and even shadowing someone who works in a prenatal or pediatric clinic; someone who primarily sees adult patients or works on a research study; someone who works in a laboratory or industry setting; or someone who works in public health outreach (e.g., education). Prepare for your application and interviews by delving into the genetic counselling literature and recent genetics news to see what's happening at the edges of the profession, where there is so much new and exciting growth. 